\title{
- Dental Caries Status of 3-6 Years Old Children in Biratnagar, Nepal: A Cross- Sectional Study

\section{Deep Jitendra Meisheri ${ }^{1}$, Ashiwn Devasya ${ }^{2}$, Bhushan Bhattarai ${ }^{3}$, Ravi Acharya ${ }^{4}$}

\author{
'Lecturer, Department of Pedodontics and Preventive Dentistry, Nobel Medical College Teaching Hospital, Kanchanbari, Biratnagar-4, Morang, \\ Nepal; 'Sr. Lecturer, Department of Pedodontics and Preventive Dentistry, Kannur Dental College, Anjarakkandy, Kannur, Kerala State, India.; \\ ${ }_{3}^{3}$ Lecturer, Department of Orthodontics, Nobel Medical College Teaching Hospital, Kanchanbari, Biratnagar-4, Morang, Nepal; ‘ Lecturer, Depart- \\ ment of Conservative Dentistry and Endodontics, Nobel Medical College Teaching Hospital, Kanchanbari, Biratnagar-4, Morang, Nepal.
}

\section{ABSTRACT}

Background: Dental caries persists as one of the most prevalent chronic diseases among children worldwide. In preschool age children, this form of dental caries is termed as Early Childhood Caries (ECC). The objective of this study is to determine the frequency of dental caries among preschool children of Biratnagar, Nepal.

Methods: A cross-sectional study of 1382 preschool children was conducted in Biratnagar, Nepal. Children were randomly selected from government run preschools in Biratnagar. Children between 3-6 years age group were assessed for dental caries. Data was analyzed using SPSS version 16.0 software.

Results: Out of the 1382 children examined, 894(64.86\%) had caries out of which $501(56.04 \%)$ were males and 393(43.95\%) females. The overall mean deft for ECC was 2.93 22.17 ranging from 0-16. Severe-ECC was present in $39.59 \%$ (354 out of 894 ) of caries positive children. Dental plaque was present in $931(67.36 \%)$ children. $279(20.18 \%)$ children had poor oral hygiene.

Conclusion: More than half of the preschool children had early childhood caries. Association between age of the child, dental plaque and poor oral hygiene has been established. There is an urgent need for preventive and curative oral health programs for children in Nepal.

Key Words: Dental caries, Preschool children, ECC, s-ECC, Nepal

\section{INTRODUCTION}

Dental caries persists as one of the most prevalent chronic diseases among children worldwide. Dental caries also interferes with the healthy life of both children and adolescents. Dental caries is defined as a multifactorial microbial disease characterized by demineralization of the inorganic and destruction of the organic substance of the tooth. ${ }^{[1]}$ Dental caries in preschool age children is termed as Early Childhood Caries (ECC). According to American Academy of Pediatric Dentistry (AAPD), ECC is defined as the presence of one or more decayed (non-cavitated or cavitated lesions), missing (due to caries) or filled tooth surfaces in a child 71 months of age or younger. In children younger than 3 years of age, any sign of smooth surface caries is indicative of severe early childhood caries (s-ECC). ${ }^{[1,2]}$

Children with ECC and s-ECC have a poor quality of life due to pain, premature loss of teeth, malnutrition, distress and functional restrictions. ${ }^{[3]}$ The incidence of dental caries among preschool children of developed countries has been declining. However, $90 \%$ of preschool children in Asia are affected by dental caries. ${ }^{[4]}$ There is a lack of definite data on incidence of ECC and s-ECC at both national and local levels in the city of Biratnagar, Nepal. Therefore the aim of the present study is to measure the incidence of dental caries among 3-6 years old children of Biratnagar, Nepal.

\section{Corresponding Author:}

Dr. Deep Jitendra Meisheri, Lecturer, Department of Pedodontics and Preventive Dentistry, Nobel Medical College Teaching Hospital, Kanchanbari, Biratnagar- 4, Morang, Nepal; Ph: +977-9805335639(Nepal); Email: dj.meisheri@gmail.com

ISSN: $2231-2196$ (Print)

Received: 06.06.2018
ISSN: 0975-5241 (Online)

Revised: 14.06.2018
Accepted: 28.06.2018 


\section{METHODS}

A cross sectional study was conducted in Biratnagar, Nepal during the period of Jan-April, 2018. The study was conducted after approval from institutional ethical review committee. Informed consent explaining the nature of the study was obtained from the parents and headmasters of the schools.3-6 years old children of both genders from government run preschools were included in the study. Children above 6 years of age having at least one permanent tooth or suffering from periodontal conditions or any systemic disease or were absent on the day of examination were excluded from the study.

A total of 1382 children attending government run preschools were clinically examined for diagnosis of ECC and s-ECC according to deft index. The WHO criterion was used for diagnosis of dental caries. ${ }^{[4]}$ The presence of dental plaque and assessment of oral hygiene was assessed solely through visual examination without using any universally accepted index system as it was not the prime objective of the study.

Caries severity was assessed via deft index by categorizing the score into very mild (1 tooth), mild (2-3 teeth), moderate (4-5 teeth) and severe (more than 6 teeth). The examination of the children was done by single calibrated examiner with the child seated in a normal chair or in knee to knee position depending on the behavior of the child. The examination was carried out using sterilized mouth mirror and explorer in natural light. In questionable cases the tooth was marked as sound. No radiographs were taken.

SPSS version16.0 software was used to enter and analyze the data. Chi-square test and ANOVA were used to find significance. $\mathrm{P}$ value of $<0.05$ was considered as statistically significant.

\section{RESULTS}

Out of the 1382 children examined, 719(52.02\%) were boys and 663(47.97\%) were girls. The overall prevalence of caries in the study population was $64.68 \%$ ( 894 children). Out of the $894(100 \%)$ children with ECC, $56.04 \%$ (501) were boys and $43.95 \%$ (393) were girls [see Table No.1]. No significant differences were observed in ECC affected children based on gender $(\mathrm{P}=0.31)$. Whereas prevalence of ECC was significantly higher among 3-4 years children as compared to other age groups $(\mathrm{P}=0.001)$.

Out of the 51\% children with ECC, 39.59\% (354 children) had s-ECC out of which $54.23 \%$ (192) were boys and $45 \%$ (162) were girls. No significant gender difference was found $(\mathrm{P}=0.47)$ [see Table 2]. There was also no significant difference among different age groups $(\mathrm{P}=0.44)$.
The overall mean deft score was $2.93( \pm 2.17)$ of which decayed component comprised of $1.87( \pm 2.73)$, extracted component $1.12( \pm 0.61)$ and filled component only 0.79 $( \pm 0.213)$. The mean deft of boys was $3.18( \pm 3.02)$ and girls was $2.63( \pm 2.54)$ [see Table 3].

Out of the 1382 children examined $27.06 \%$ had one tooth involved (very mild), $11.79 \%$ had 2-3 teeth involved (mild), $14.83 \%$ had $4-5$ teeth involved (moderated) and only $10.99 \%$ had more than 6 teeth affected (severe). Dental plaque was clearly visible in $67.36 \%$ children and $20.18 \%$ children had poor oral hygiene [see Table 4].

\section{DISCUSSION}

A total of 1382 children aged 3-6 years were examined for ECC from various government run preschools in and around Biratnagar. The statistics of this study revealed that almost $65 \%$ of 3-6 years old children suffered from ECC which is way below the WHO goals i.e. $50 \%$ of the preschool children should be caries free. ${ }^{[5]}$ This is high compared with neighboring countries where the prevalence of ECC ranges from $37.64-52.31 \%$ in India to $43.01-51.4 \%$ in China. The highest prevalence of ECC was $85.5 \%$ in rural china. ${ }^{[6.78]}$ These could be attributed to differences in socio-economic, cultural, nutrition, dietary habits and oral hygiene patterns. The prevalence of ECC worldwide was found to be highly variable ranging from $11-53.1 \%$ in USA, $6.8-12 \%$ in UK to $2.1 \%$ in Sweden. ${ }^{[9-14]}$ This could be due to differences in case definitions and diagnostic criteria

An important finding of this study was that about $39.59 \%$ of children with ECC showed s-ECC. Only 3.9\% of all decayed teeth were filled where as $1.2 \%$ primary teeth were extracted due to caries. Another important finding of this study was that all the children with ECC showed untreated dental caries and required treatment. This proves a lack of awareness about oral health among parents and government bodies. Also, lack of affordability for oral health in this section of society is alarming.

Most children (79.81\%) maintained a good oral hygiene, whereas plaque accumulation was observed in $67.36 \%$ of children examined.

In the present study, there could a slight overestimation of caries experience. As the study was carried out at only government run preschools, all the children belong to poor families who have been proved to give least importance to oral health.

\section{CONCLUSION}

$64.68 \%$ of government run preschool children bear the burden of dental caries. There is an urgent need for implemen- 
tation of government aided, NGO aided and public-private partnership dental health treatment programs.

Since this was a cross-sectional study, therefore a future longitudinal study is suggested to establish association for risk factors with dental caries in Nepal.

Source of funding: the authors declare that no external source of funding was used for the study.

Conflict of interest: The authors declare that they have no conflict of interest with any person or organizations.

\section{REFERENCES}

1. AAPD: Policy on Early Childhood Caries: Classifications, consequences, and preventive strategies. Reference manual, 2011; 34(6): 50 .

2. Milnes AR. Description and epidemiology of nursing caries. J Public Health Dent 1996; 56(1):38-50.

3. Pahel BT, Rozier RG, Slade GD. Parental perceptions of children's oral health: the Early Childhood Oral Health Impact Scale (ECOHIS). Health Qual Life Outcomes 2007; 5:6.

4. Du RY, Mcgrath C, Yiu, CKY, King NM. Health- and oral health -related quality of life among preschool children with cerebral palsy. Qual Life Res 2010; 19(9):1367-1371.

5. Kassebaum,N.J.;Bernabé,E.;Dahiya,M.;Bhandari,B.;Murray,C. ;Marcenes, W.Globalburdenofuntreated caries: A systematic review and metaregression. J. Dent. Res. 2015, 94, 650-658.

6. Kumarihamy, S.L.; Subasinghe, L.D.; Jayasekara, P.; Kularatna, S.M.; Palipana, P.D. The prevalence of early childhood caries in 1-2 years old in a semi-urban area of Sri Lanka. BMC Res. Notes 2011, 4, 336.

7. Abdullah S, Qazi HS, Maxood A: Dental caries status in 6-9 years old children. Pak Oral Dent J 2008, 28:107-112.

8. Stella YLK, Petersen PE, Pine CM, Borutta A: Health-promoting schools: an opportunity for oral health promotion. Bull WHO 2005, 83:677-685.

9. Currie C, Hurrelmann K, et al: Health and health behaviors among young people. Copenhagen; WHO regional office for Europe; 2000 WHO policy series. Health policy for children and adolescents, (1). International report. http://www.euro.who. int/ data/assets/pdf file/0006/119571/E67880.pdf. Accessed on 30th April 2011.

10. Pitts NB, Chestnutt IG, Evans D, White D, Chadwick B, Steele JG, et al: The dentinal caries experience of children in the United Kingdom, 2003. Brit Dent J 2006, 200:313-320.

11. Hugoson A, Koch G, Helkimo AN, Lundin SA: Caries prevalence and distribution in individuals aged 3-20 years in Jonkoping, Sweden, over a 30-year period (1973-2003). Int J Paediatr Dent 2008, 18:18-26. 6. Wyne AH: Caries prevalence, severity, and pattern in preschool children. J Contemp Dent Pract 2008, 3:024-031.

12. Mahejabeen R, Sudha P, Kulkarni SS, Anegundi R: Dental caries prevalence among preschool children of Hubli: Dharwad city. J Indian Soc Pedod Prev Dent 2006, 24:19-22.

13. Charani A, Mohsin S, Sufia S, Khan AA: Prevalence of early childhood caries among 3-5-year old children of Clifton, Karachi. J of Pak Dent Assoc 2011, 20:89-92.

14. Sufia S, Chaudhry S, Izhar F, Syed A, Mirza BA, Khan AA: Dental caries experience in preschool children: is it related to a child's place of residence and family income? Oral Health Prev Dent 2011, 9(4):375-379.

Table 1: Gender and age wise prevalence of ECC

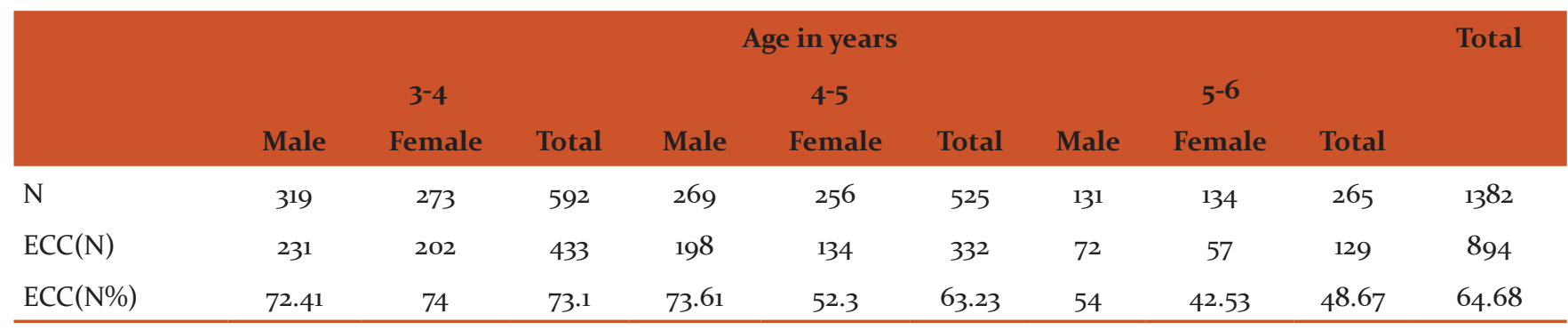

Table 2: Age and Gender wise prevalence of s-ECC

\begin{tabular}{|c|c|c|c|c|c|c|c|c|c|c|}
\hline & \multicolumn{9}{|c|}{ Age in years } & \multirow[t]{3}{*}{ Total } \\
\hline & \multicolumn{3}{|c|}{$3-4$} & \multicolumn{3}{|c|}{$4-5$} & \multicolumn{3}{|c|}{$5-6$} & \\
\hline & Male & Female & Total & Male & Female & Total & Male & Female & Total & \\
\hline $\mathrm{N}$ & 231 & 202 & 433 & 198 & 134 & 332 & 72 & 57 & 129 & 894 \\
\hline $\mathrm{s}-\mathrm{ECC}(\mathrm{N})$ & 92 & 67 & 159 & 73 & 79 & 152 & 27 & 16 & 43 & 354 \\
\hline s-ECC(N\%) & 39.82 & 33.16 & 36.72 & 36.86 & 58.95 & $45 \cdot 78$ & $37 \cdot 5$ & 28.07 & $33 \cdot 33$ & 39.59 \\
\hline
\end{tabular}


Table 3: distribution of variables regarding dental caries status and cumulative $\mathrm{dmft}$

\begin{tabular}{lccc} 
Variables & $\begin{array}{c}\text { Frequency } \\
(\mathrm{N}=1382)\end{array}$ & Percent & Mean \pm SD \\
deft(cumulative) & 894 & 64.68 & $2.93 \pm 2.17$ \\
Decayed & 881 & 63.74 & $1.87 \pm 2.73$ \\
Extracted(due to caires) & 17 & 1.2 & $1.12 \pm 0.61$ \\
Filled & 54 & 3.9 & $0.79 \pm 0.213$ \\
\hline
\end{tabular}

Table 4: Severity of dental caries and status of oral health

\begin{tabular}{lcc} 
Variables & $\begin{array}{c}\text { Frequency } \\
(\mathrm{N}=1382)\end{array}$ & Percent \\
Dental caries status: & 894 & 64.68 \\
Caries positive & 488 & 35.31 \\
Caries negative & & \\
Decayed catergory for severity & 488 & 35.31 \\
o(sound) & 374 & 27.06 \\
1(1 tooth involved) & 163 & 11.79 \\
$2(2-3$ teeth involved) & 205 & 14.83 \\
$3(4-5$ teeth involved) & 152 & 10.99 \\
$4(6+$ teeth involved) & & \\
Presence of Dental Plaque & 931 & 67.36 \\
Yes & 451 & 32.63 \\
No & & \\
Poor Oral Hygiene & 279 & 20.18 \\
Yes & 1103 & 79.81 \\
No & & \\
\hline
\end{tabular}

